\title{
STRUCTURE OF PRODUCTION AND ECONOMIC POTENTIAL OF THE REGION
}

\author{
Svetlana Boguslavskay ${ }^{1}$ \\ ${ }^{I}$ Ph.D. (Economics), Associate Professor, Associate Professor, Management and Economic Security Department, \\ Bohdan Khmelnitsky National University of Cherkassy, Cherkassy, Ukraine, e-mail: boguslavskaya1980@gmail.com, \\ ORCID: https://orcid.org/0000-0002-6834-9765
}

Citation:

Boguslavskay, S. (2020). Structure of production and economic potential of the region. Economics, Finance and Management Review, (2), 16-22. https://doi.org/10.36690/2674-52082020-2-16

Received: April 27, 2020

Approved: May 29, 2020

Published: June 05, 2020

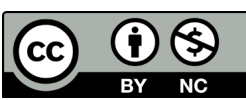

This article is an open access article distributed under the terms and conditions of the Creative Commons Attribution (CC BY-NC 4.0) license

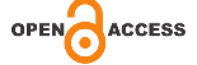

Abstract. The article considers the concepts of "economic potential of the region" and "production potential of the region", which are a factor in the economic development of the region. The article conducts a thorough study of scientific approaches to defining the definition of "economic potential of the region" and "production potential of the region" and as a result the author's definition of the concept of "production and economic potential of the region". The main differences between the author's definition and those already existing in economics are proved. Substantiated systematic approach to managing the development of the region, which in turn allows to determine the system of economic and financial indicators that characterize the state of production and economic potential of the region by structural units: financial potential; labor potential; stock potential; scientific potential; natural resource potential; institutional capacity; information and communication potential, which in turn is presented in the article in the form of a graphical diagram of the structure of production and economic potential of the region. The paper also provides a brief description of all types of potentials involved in the structure of production and economic potential of the region. The article also considers scientific approaches to the definition of fixed and working capital, analyzes their differences and similarities. Given the lack of a clear definition of the concept of fixed capital in the economic literature, the author presented his own vision of the definition of this concept, which in his opinion most fully reveals the meaning of this economic category.

Keywords: potential, development, region, capital, structure, production, economy.

JEL Classification: D60, 047

Formulas: 0; fig.: 1; tabl.: 0; bibl.: 6

Introduction. Scientific interest in studying the economic content of the production and economic potential of the region is due to the peculiarities of modern regional policy. Currently, the regions have relative economic independence in making management decisions, which has increased the responsibility of administrative bodies for the financial results of the state entity, as the lack of industrial production can eventually lead to depression in the region.

At the present stage of development of the national economy the intensification of the production potential of enterprises, industries and territorial complexes, its quantitative definition and practical use in the regulation of production relations is actualized.

The need for immediate solution of these problems stems from the requirements of objective economic laws. But so far no single methodological approach has been identified that reflects the content of this problem.

Literature review. Problems of functioning and development of production and economic potential were first revealed in the works of foreign scientists: F. Quesnay, A. Smit, K. Marx, A. Marshall, J. Schumpeter, P. Somuelson and many others. 
Among domestic regional scientists are O. Dovgal, A. Gavrilenko, O. Kolomytseva, M. Makarenko, M. Mylenky, V. Savchenko, and others.

In the scientific literature, scientists and practitioners differently delineate the boundaries of production and economic potential of the region. Thus, this problem is currently unsolved and requires further scientific research.

Aims. The purpose of the article is to study a set of elements of production and economic structure of the region in a market economy.

Methods. The methodological basis of the study was a systematic and abstractlogical approaches - in the study of theories, discussions, assumptions on the nature, structure, definition of production and economic potential and fixed capital, which allowed to determine the meaning and patterns of theoretical aspects of the problem.

Results. The structure of production and economic potential of the region is a set of connections and relationships that have developed in the production process, on which depends the sustainable development of the region. Elements of production and economic potential of the region are not only in close cooperation, but also divided as they are interdependent.

Production and economic potential of the region is not a mechanical connection, but a dynamic combination of interdependent elements, and the degree of their alternative does not remain constant, but varies depending on the economic situation, the level of development of production potential, the economic system of the region.

The author finds that the production potential of the economic system is represented by its objective ability to produce products, generate income based on resource balance of interconnected elements involved in the production process. In this case, the production potential is a total assessment of the maximum possible effectiveness of the use of resources by enterprises of industries in the region in terms of rational organization of production to the interaction of economic entities.

The more complex the structure of production potential as a holistic economic system, the more diverse the methods of influencing the economic processes of government.

Regarding the economy of the region, the analogue of the concept of "production and economic potential of the region" is the phrase "economic potential of the region" and "production potential of the region", which in our study act as factors of its development.

According to O. Dovgal, the production potential is a system of economic relations that have arisen between economic entities at the macro and micro levels to obtain the maximum possible economic result with the most efficient use of resources by enterprises, the current level of equipment and technology, advanced forms of production and labor, environmental factors (Dovgal, O., 2019).

According to M. Makarenko, production and economic potential is the ability of economic entities in market conditions to produce the optimal amount of competitive products with the efficient use of balanced resources, a high level of management and marketing from the standpoint of a reproductive approach (Makarenko, M., 2017).

The Economic Dictionary interprets the essence of production potential as follows: "Production potential is available and potential production opportunities, the 
presence of factors of production, the provision of its defining types of resources" (Economic Glossary: Property, Privatization, Securities Market, 2003).

The author considers the production potential of the region as an integral part of the economic development of the region, as its condition and possible qualitative and quantitative changes determine the achievement of the necessary growth of production and increase the welfare of the population of the region.

All concepts have to some extent been studied and refined by foreign and domestic economists. From modern interpretations, the logic and methodology of these studies is based on the definition in which the economic potential of the region means the total ability of the region's economy, its industries, enterprises, farms to carry out production and economic activities, produce products, goods, services, meet public needs. to ensure the development of production and consumption.

Studies have shown that the main purpose of the production and economic condition of the region is to increase the level of socio-economic development, increase gross regional product.

Thus application of an integrated indicator of an estimation of industrial and economic potential of region will allow to receive comparable and objective results of the analysis of industrial and economic development of region. Integral assessment of production and economic potential, expresses the essence of internal evaluation. It is determined based on the parameters that assess the internal structure of production capacity. These parameters are defined as dependent on external and internal factors and assess the level and condition of a particular element of production potential.

Researchers of problems of estimation of production and economic potential allocate various components in structure of aggregate branch potential. Analysis of scientific works and practical experience in assessing the production and economic potential, approaches to assessing its structure led to the need to develop a system of general and specific indicators that characterize the state of production and economic potential for seven structural blocks: stock, financial, labor, scientific, institutional and natural resources, as well as indicators of the information and communication component. The author's vision of the structure of production and economic potential of the region is presented in Fig. 1.

According to the author, this approach will identify market opportunities in the region and contribute to the realization of identified opportunities while maximizing the potential of enterprises, which is provided by fixing each block of tasks and available economic resources of the region.

When assessing the production and economic potential of the region in modern conditions, the exceptional importance of the stock potential, expressed in the form of fixed capital of enterprises, ie the material factors of regional economic development involved directly in the production process, is especially obvious. From this point of view, the modernization of stock potential in the economic structures of the region is a fundamental factor, and is of great economic importance and determines the rate of economic growth in the short and long term. And although the effective use of stock potential is only one of the conditions for ensuring a sustainable pace of socioeconomic development, this condition is very important because the structure of 
investment not only determines capital growth, but also forms the basis for development of both productive and non-productive spheres. This problem is especially evident in the regional context.

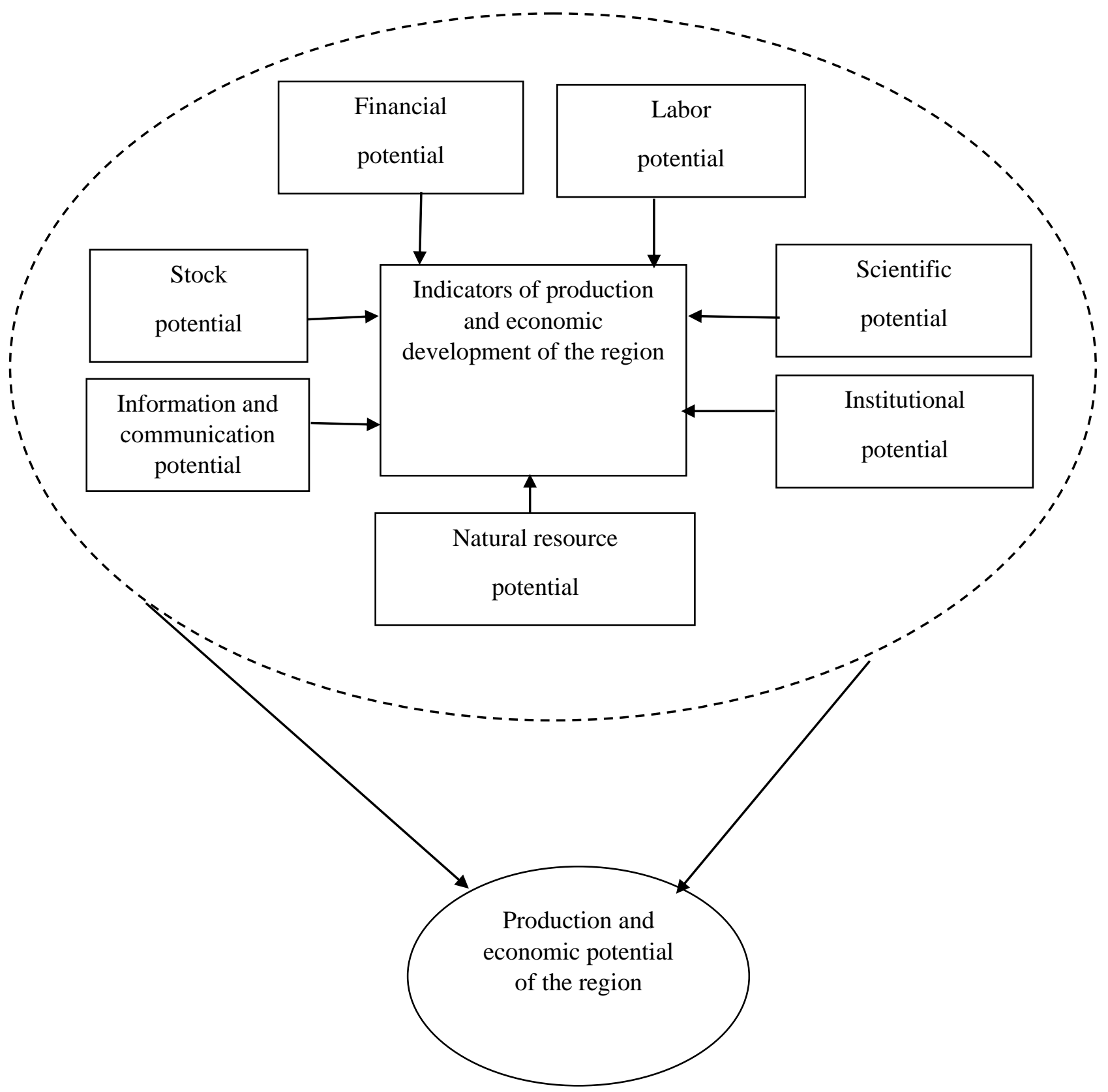

Figure 1. The structure of production and economic potential of the region Source: developed by authour

However, paradoxically, the tools of practical management of the formation and use of stock potential in the economic activity of the enterprise has been developed so far quite unfounded.

In the unstable conditions of the economy, the fixed capital of economic entities (the main element of the stock potential) is obsolete, its technological and reproductive structure has deteriorated. Most of them do not have the funds to upgrade fixed assets, especially its active part, to the greatest extent requires timely renewal, taking into account not only physical but also moral deterioration. 
Fixed capital refers to productive capital. The methodology of reproduction of productive capital is based on the logistical sequence of circulation and foreign trade turnover of industrial capital. As part of the individual reproduction of industrial capital carries out its range and productive capital.

The economic category of "fixed capital" belongs to a complex category, which includes such categories as material and moral depreciation, depreciation, reimbursement and renewal, circulation and turnover of capital.

nterpretation of the content of the category "fixed capital" is ambiguous among economists. Differences between the components of capital in the nature of turnover were noted by physiocrats (Quesnay, Turgot) (Petti, V., 2000). The capital invested in agriculture, they divided into "initial advances" and "annual advances".

Note that the concept of fixed capital was first introduced into the economy by A. Smith (Petti, V., 2000). A. Smith applied the category of fixed and working capital to all working capital, regardless of the industry in which it is used. However, working capital he mistakenly understood commodity and money capital, ie capital in its forms, which belong to the sphere of circulation. Fixed capital is generally noncurrent, and working capital is continuously in circulation.

In fact, fixed and working capital are two types of productive capital. They differ from each other in the ways in which their value is returned. The value of fixed capital is transferred in parts to the manufactured goods, and the value of working capital is fully included in this product.

D. Ricardo adhered to the positions of A. Smith on capital as a production stock, food stocks, raw materials and tools of production (Petti, V., 2000). The social nature of capital was not shown to them.

Marx made a significant contribution to the development of the theory of capital. He considers capital as a socio-economic category.

K. Marx considered the production process from a dialectical point of view. Under dialectics, he understood the doctrine of sustainable development in its most complete, profound and one-sided form, the doctrine of the relativity of human knowledge, which gives us a reflection of eternal development (Marks, K., 1955).

In modern economic theory there is still no unambiguous interpretation of the concept of capital, the process of its formation continues, and this, in turn, is reflected in the development of methods of economic analysis.

Most domestic authors identify the concept of "fixed capital" and "fixed assets". Some authors, giving a definition of fixed capital, do not identify these concepts, but do not give a clear definition of what elements should be attributed to fixed capital.

Given the lack of clear definition in the economic literature of the concept, we believe that the most complete meaning of this economic category reveals the following definition: fixed capital - part of the capital of the enterprise, which is invested in all types of non-current assets, including fixed assets, intangible assets, unfinished construction, long-term financial investments and other non-current assets in order to focus on the innovation and technical trajectory of development.

Unlike other elements of the production and economic potential of the region, the financial potential has a number of features. This indicator has a great influence 
on the formation of other elements of production and economic potential. Financial resources, an important source of which is profit, are the main tool for the reproduction of all elements of production potential. Therefore, the analysis and evaluation of financial indicators as an element of production and economic potential should be carried out from the standpoint of providing a particular sector of the region with financial resources and their efficient use.

The quality of human capital in the region is expressed by the level of labor potential. Therefore, in the context of our study, the level and ways to increase labor potential are of interest based on the need for sustainable movement to the innovative vector of economic development of the region.

The next component in the assessment of the integrated indicator of production and economic potential of the region is the information and communication component (ICT), which includes a system of information and computing services, which has a great influence on the nature of the region.

In fact, due to ICT, information flows become an information resource of the region. It should be remembered that the management of the region is a constant cyclical process of making management decisions and initiating information flows. Therefore, for the long-term development of the region it is necessary to update and design the process of investing in ICT. Thus, ICT and the construction of information and computer services have a great influence on the nature of the functioning of individual enterprises, industries, industries, and the whole region. Regular circulation of information is necessary for the management of the region, which, in fact, ensures the process of using ICT.

A component of the production and economic potential of the region is also the scientific potential, as it is a set of resources that the industry has to carry out production and innovation activities. The scientific potential of the region is in the form of a complementary set of its intellectual and material resources that can contribute to the generation and dissemination of new knowledge, as well as the effective borrowing and assimilation of knowledge obtained from others (Esimov, C., 2015). The resource component takes into account only the number of employees engaged in scientific activities and their professional qualifications.

According to the author, in the system of components of production and economic potential for its assessment it is important to use the institutional potential. Note that the understanding of the category "institution" includes a set of heterogeneous economic phenomena: procedures and rules of conduct, sanctioned by law or custom; lawful or regulated norms that protect the interests of market participants; organizations and administrative (political) structures; institutions in the broadest sense of the word, including culture and mentality.

Assessment of production and economic potential is exclusively dependent on the impact of natural resource potential. In the process of economic development of the region there are quantitative and qualitative changes in the natural resource potential of the region. Preservation, expedient and complex use of this potential is one of the main tasks of rational nature management. 
Discussion. Based on the above, the author considers it necessary to clarify and supplement the concept of "production and economic potential of the region." The author's definition of "production and economic potential" can be represented as a set of organically interconnected existing and potential production opportunities, characterized by systemic unity of resources, scale and condition of the technical base of the economic system, efficient functioning of socio-economic institutions and rational use of natural resources potential.

Conclusion. The proposed author's definition of "production and economic potential of the region" differs from the existing capacity and breadth of interpretation of the essence of production and economic potential, it reflects the structure of production potential which is characterized by the unity of the system and reflects the flow of its functioning. This objectively increases the attention to the development and use of methods for assessing production capacity. Note that the definition of a single aggregate indicator that takes into account the state, movement and efficiency of each of the elements of production capacity and allows to investigate the causal relationships in the state of production capacity in general, is associated with one of the important principles of assessing production potential.

\section{References:}

1. Dovgal, O. (2019). Production potential of rural areas: the state and level of use in terms of food security in the region. Economic and Food Security of Ukraine, 6(3-4), 65-73. URL://doi.org/10.15673/efs.v6i34.1288 .

2. Economic Glossary: Property, Privatization, Securities Market (Ukrainian-English-Russian) / L. Alekseenko, V. Oleksienko. - Ternopil: Aston. 2003. 672.

3. Esimov, C. (2015) The use of information technology as a subject of administrative and legal regulation. Bulletin of the National University "Lviv Polytechnic". Legal sciences. № 827. 24-29.

4. Makarenko, M. (2017) Economic potential of the region as a basis for its development. Bulletin of the Azov State Technical University: a collection of scientific papers. №. 34. 12-18.

5. Marks, K. (1955) Poverty of philosophy. M.: The State Publishing House is watered. liters. 65-185.

6. Petti, V. (2000) Tax treaty. M.: EXMO-Press. 7-79. 